\title{
Crescimento, índices fisiológicos e produtividade de cultivares de feijoeiro sob diferentes níveis de adubação
}

\author{
Letícia Andriani dos Santos $^{* 1}$, Rogério Peres Soratto ${ }^{2}$, Adalton Mazetti Fernandes ${ }^{3}$, Jaqueline Regiani Gonsales ${ }^{1}$ \\ http://dx.doi.org/10.1590/0034-737X201562010014
}

\section{RESUMO}

Conhecimentos sobre o acúmulo e a distribuição da fitomassa do feijoeiro comum, sob diferentes níveis de adubação, podem auxiliar no manejo da cultura. Este trabalho objetivou avaliar o crescimento, os índices fisiológicos e a produtividade de cultivares de feijão, sob diferentes níveis de adubação NPK. O experimento foi conduzido em um Nitossolo Vermelho distroférrico, no município de Botucatu, SP, no delineamento experimental de blocos casualizados, em parcelas subdivididas, com quatro repetições. As parcelas foram constituídas por seis tratamentos ('Pérola', sem adubação; 'Pérola', com 50\% da adubação recomendada; 'Pérola', com 100\% da adubação recomendada; 'IAC Alvorada', sem adubação; 'IAC Alvorada', com 50\% da adubação recomendada e 'IAC Alvorada', com 100\% da adubação recomendada) e, as subparcelas, por sete épocas de coletas no decorrer do ciclo. A adubação NPK aumentou os acúmulos de matéria seca, os componentes da produção e a produtividade de grãos dos cultivares Pérola e IAC Alvorada de forma semelhante. O cultivar IAC Alvorada apresentou maiores índices de área foliar e matéria seca de folhas, quando comparados com os de Pérola, sob adubação NPK recomendada, porém, sem esses índices refletirem-se em maior produtividade de grãos. O máximo acúmulo de matéria seca foi alcançado aos 80 DAE e a maior taxa de crescimento da cultura ocorreu aos 55 DAE, independentemente do tratamento.

Palavras-chave: Phaseolus vulgaris L., análise de crescimento, partição de matéria seca, índice de área foliar, taxa de crescimento.

\section{ABSTRACT \\ Growth, physiological indices and yield of common bean cultivars under different levels of fertilization}

Knowledge of the accumulation and distribution of phytomass in common bean plants under different levels of fertilization can improve crop management. The objective of this study was to evaluate growth, physiological indices and yield of common bean cultivars under different levels of NPK fertilization. The experiment was carried out on a dystroferric Red Nitosol, in Botucatu, State of São Paulo, in a split plot randomized block design, with four replications. Plots were constituted of six treatments (Pérola without fertilization, Pérola with 50\% of recommended fertilization, Pérola with $100 \%$ of recommended fertilization, IAC Alvorada without fertilization, IAC Alvorada with $50 \%$ of recommended fertilization, and IAC Alvorada with $100 \%$ of the recommended fertilization) and subplots were made up by seven harvest times during the growth cycle. The NPK fertilization increased similarly the dry matter accumulation, yield components, and grains yield of cultivars of Pérola and IAC Alvorada. Under recommended fertilization, IAC Alvorada cultivar showed higher leaf area index and leaf dry matter accumulation

Submetido em 19/02/2013 e aprovado em 18/12/2013.

${ }^{1}$ Universidade Estadual Paulista, Faculdade de Ciências Agronômicas, Botucatu, São Paulo, Brasil. leticiaandriani@ hotmail.com

${ }^{2}$ Universidade Estadual Paulista, Faculdade de Ciências Agronômicas, Departamento de Produção e Melhoramento Vegetal, Botucatu, São Paulo, Brasil.

${ }^{3}$ Universidade Estadual Paulista, Centro de Raízes e Amidos Tropicais, Botucatu, São Paulo, Brasil. adalton@ cerat.unesp.br

*Autor para correspondência: soratto@ fca.unesp.br 
than Pérola; however, with no effects on the increase of grain yield. Regardless of treatment, the maximum dry matter accumulation was achieved at $80 \mathrm{DAE}$ and the highest crop growth rate occurred at 55 DAE.

Key words: Dry matter partitioning, growth analysis, growth rate, leaf area index, Phaseolus vulgaris L.

\section{INTRODUÇÃO}

O feijão (Phaseolus vulgaris L.) destaca-se como a principal fonte de proteína da maioria da população brasileira, além de apresentar bom conteúdo de carboidratos e ser rico em ferro (Fe) (Borém \& Carneiro, 2006).

Nas condições nacionais, o feijoeiro é cultivado praticamente o ano todo, em diferentes épocas e nos mais variados sistemas de cultivo (Zucareli et al., 2010), por agricultores que utilizam de alta tecnologia, incluindo cultivares mais produtivos, irrigação, população de plantas adequada e maiores níveis de adubação, o que permite a obtenção de produtividades de grãos superiores a 3.000 $\mathrm{kg} \mathrm{ha}^{-1}$ (Vieira, 2006). Contudo, na maioria das vezes, o feijão ainda é produzido por pequenos agricultores, os quais utilizam poucos recursos tecnológicos e baixos níveis de adubação (Borém \& Carneiro, 2006), o que se refletem em baixos níveis de produtividade.

Dentre os principais cultivares de feijão com grãos "tipo carioca", destaca-se o Pérola, um dos mais cultivados no Brasil e que é referência quanto à produtividade e à qualidade dos grãos (Melo et al., 2006), os quais são preferidos pelas empresas empacotadoras e pelo consumidor final, que definem as exigências de mercado. O cultivar IAC Alvorada, lançado em 2007, também apresenta elevado potencial produtivo e excelente qualidade dos grãos, além de moderada tolerância à antracnose (Carbonell et al., 2008; Soratto et al., 2011). Ambos os cultivares têm hábito de crescimento tipo III.

Cada genótipo tem um potencial máximo de produtividade. No entanto, fatores ambientais, como a disponibilidade de nutrientes, impõem limitações e a produção, normalmente, é menor que o potencial. Desse modo, a produtividade de uma cultura depende de inter-relações complexas entre plantas individuais, comunidades de plantas e o ambiente, que se manifestam por meio de processos fisiológicos (Conceição et al., 2004).

A análise de crescimento pode ser empregada na avaliação dos efeitos dos fatores ambientais e do manejo sobre as plantas, pois descreve as mudanças na produção vegetal em função do tempo, bem como a contribuição dos diferentes órgãos no crescimento total das plantas, o que não é possível com o simples registro da produtividade final (Urchei et al., 2000; Benincasa, 2003, Jauer et al., 2003; Andrade et al., 2009). O acúmulo de matéria seca (MS) e sua distribuição na planta são processos importantes na definição da produtividade final da cultura (Andrade et al., 2009). Contudo, pouco se conhece sobre o efeito de níveis de adubação no crescimento e na produtividade de grãos dos principais cultivares de feijão utilizados atualmente.

Este trabalho objetivou avaliar o crescimento, os índices fisiológicos e a produtividade de grãos dos cultivares de feijão Pérola e IAC Alvorada, sob diferentes níveis de adubação NPK.

\section{MATERIAL E MÉTODOS}

O experimento foi conduzido no ano agrícola 2010/ 2011, no município de Botucatu, SP (48 26’ W, $22^{\circ} 51^{\prime} \mathrm{S}$ e $740 \mathrm{~m}$ de altitude). O clima predominante na região é do tipo Cwa, segundo a classificação climática de Köppen, caracterizado como tropical de altitude, com inverno seco e verão quente e chuvoso. Aárea onde o experimento foi instalado vem sendo cultivada há vários anos no sistema de plantio direto. Antes da instalação do experimento a área foi cultivada com a sequência trigo-milhomilheto.

O solo do local é um Nitossolo Vermelho distroférrico, cujos resultados de análises químicas, da camada de 0-20 $\mathrm{cm}$ de profundidade, foram: $28 \mathrm{~g} \mathrm{dm}^{-3}$ de matéria orgânica; $\mathrm{pH}\left(\mathrm{CaCl}_{2}\right)$ 5,0; $33 \mathrm{mg} \mathrm{dm}^{-3} \mathrm{de} \mathrm{P}$ (resina) ; 3,0 $\mathrm{mmol}_{\mathrm{c}} \mathrm{dm}^{-3} \mathrm{de}$ K trocável; $25 \mathrm{mmol}_{\mathrm{c}} \mathrm{dm}^{-3}$ de Ca trocável; $11 \mathrm{mmol}_{\mathrm{c}} \mathrm{dm}^{-3} \mathrm{de}$ $\mathrm{Mg}$ trocável; $32 \mathrm{mmol}_{\mathrm{c}} \mathrm{dm}^{-3} \mathrm{de} \mathrm{H}+\mathrm{Al}$; saturação por bases (V\%), 55\%; 6,4 $\mathrm{mg} \mathrm{dm}^{-3}$ de $\mathrm{S} ; 0,40 \mathrm{mg} \mathrm{dm}^{-3}$ de B (água quente); 12,4 $\mathrm{mg} \mathrm{dm}^{-3}$ de $\mathrm{Cu} ; 23 \mathrm{mg} \mathrm{dm}^{-3}$ de Fe; 5,1 mg $\mathrm{dm}^{-3}$ de $\mathrm{Mn}$; e $1,6 \mathrm{mg} \mathrm{dm}^{-3}$ de $\mathrm{Zn}$. O B e os demais micronutrientes foram extraídos por $\mathrm{BaCl}_{2}$ e DTPA, respectivamente.

O delineamento experimental foi o de blocos casualizados, em esquema de parcela subdividida, com quatro repetições. As parcelas foram constituídas por seis tratamentos (PD0 - cultivar Pérola, sem adubação; PD1 - cultivar Pérola, com 50\% da adubação NPK recomendada; PD2 - cultivar Pérola, com 100\% da adubação NPK recomendada; AD0 cultivar IAC Alvorada, sem adubação; AD1 - cultivar IAC Alvorada, com 50\% da adubação NPK recomendada e AD2 - cultivar IAC Alvorada, com 100\% da adubação NPK recomendada) e, as subparcelas, por épocas de coletas de plantas (avaliações), que foram realizadas aos 14, 28, 35, 42, 55, 70 e 90 dias após a emergência (DAE). Cada parcela foi 
constituída por cinco fileiras de $12 \mathrm{~m}$ de comprimento. Cada subparcela foi representada por seis plantas, coletadas na área útil de cada parcela, e pelas plantas adjacentes, as quais foram consideradas bordadura, ou seja, não foram coletadas nas épocas seguintes.

Nos tratamentos PD2 e AD2 (adubação recomendada), a adubação de semeadura foi feita com $20 \mathrm{~kg} \mathrm{ha}^{-1} \mathrm{de}$ $\mathrm{N}$ (ureia), $40 \mathrm{~kg} \mathrm{ha}^{-1} \mathrm{de}_{2} \mathrm{O}_{5}$ (super fosfato triplo) e 40 $\mathrm{kg} \mathrm{ha}^{-1}$ de $\mathrm{K}_{2} \mathrm{O}$ (cloreto de potássio), de acordo com a análise de solo e a recomendação de Ambrosano et al. (1997), considerando-se a produtividade de grãos esperada de 3.500 a $4.500 \mathrm{~kg} \mathrm{ha}^{-1}$. Em cobertura, aplicaramse $90 \mathrm{~kg} \mathrm{ha}^{-1}$ de $\mathrm{N}$ (ureia), considerando-se a área como de alta resposta ao N (Ambrosano et al., 1997). Nos tratamentos PD1 e AD1 (50\% da dose recomendada), foram aplicados $10 \mathrm{~kg} \mathrm{ha}^{-1} \mathrm{de} \mathrm{N}$ (ureia), $20 \mathrm{~kg} \mathrm{ha}^{-1} \mathrm{de}_{2} \mathrm{O}_{5}$ (super fosfato triplo) e $20 \mathrm{~kg} \mathrm{ha}^{-1} \mathrm{de}_{2} \mathrm{O}$ (cloreto de potássio) na semeadura e $45 \mathrm{~kg} \mathrm{ha}^{-1} \mathrm{de} \mathrm{N}$ na cobertura (ureia).

A semeadura foi realizada mecanicamente em 15/ 02/2011, no espaçamento de $0,45 \mathrm{~m}$, com 15 sementes viáveis por metro de sulco. Em todos os tratamentos, as sementes foram tratadas com o fungicida carbendazim + tiram $(45+105 \mathrm{~g}$ do i.a. por $100 \mathrm{~kg}$ de sementes), inseticida tiametoxam ( $75 \mathrm{~g}$ do i.a. por 100 $\mathrm{kg}$ de sementes). A emergência das plântulas ocorreu em 22/02/2011. A adubação nitrogenada de cobertura foi parcelada em duas vezes, aos 14 DAE (estádio $V_{4}$ ) e aos 24 DAE (estádio $V_{4-6}$ ). A irrigação e o manejo fitossanitário da cultura durante todo o ciclo foram realizados de acordo com a necessidade e as recomendações técnicas para a cultura na região.

O florescimento pleno de ambos os cultivares ocorreu 37 DAE. Nesta ocasião, foi amostrada, em dez plantas por parcela, a terceira folha com pecíolo (Ambrosano et al., 1997). O material foi secado em estufa, a $65^{\circ} \mathrm{C}$, e as folhas foram moídas para determinação dos teores de macronutrientes (Malavolta et al., 1997).

Em cada época de coleta, foram amostradas, em cada parcela, a parte aérea de seis plantas, com ausência de sintomas de ataque de pragas e de doenças, e que apresentavam, de todos os lados, plantas competitivas. As plantas amostradas foram separadas em caule, folhas e estruturas reprodutivas (quando presentes). $\mathrm{O}$ número de folhas e a área foliar por planta foram determinados e cada parte das plantas foi secada em estufa de circulação forçada de ar, a $65^{\circ} \mathrm{C}$, e pesada.

No final do ciclo (90 DAE), foram avaliados, em duas fileiras de $3 \mathrm{~m}$ da área útil de cada parcela, os componentes da produção (população final de plantas, número de vagens por planta, número de grãos por vagem, massa de 100 grãos) e a produtividade de grãos em $\mathrm{kg} \mathrm{ha}^{-1}(13 \%$ de umidade).
Os dados de MS e área foliar, associados às épocas de coleta de plantas, e população final de plantas foram usados para a obtenção das curvas de acúmulo de MS e de índices de área foliar (IAF) (Gomes et al., 2000). As taxas de crescimento das estruturas reprodutivas (TCERs) e da cultura (TCCs) foram obtidas por meio da derivada primeira das equações de ajuste das quantidades de MS acumuladas nas estruturas reprodutivas e na parte aérea. Os valores da taxa de crescimento relativo (TCR), da taxa de assimilação líquida (TAL), da razão de área foliar (RAF), da razão de massa foliar (RMF) e da área foliar específica (AFE) foram calculados segundo Benincasa (2003).

Os dados obtidos foram submetidos à análise de variância. As médias dos tratamentos, em cada época de coleta, foram comparadas pelo teste de t (DMS), a $5 \%$ de probabilidade. Os efeitos das épocas de coletas de plantas foram avaliados por meio de análise de regressão.

\section{RESULTADOS E DISCUSSÃO}

A adubação NPK proporcionou maiores teores de N e $\mathrm{K}$ nas folhas dos cultivares de feijão, independentemente da quantidade aplicada (Tabela 1). Os teores foliares de P, Ca e S não sofreram influência dos tratamentos estudados, o que, no caso do $\mathrm{P}$, é resultado dos teores médios de $\mathrm{P}$ no solo (33 $\mathrm{mg} \mathrm{dm}^{-3}$ ) (Raij et al., 1997). Os cultivares estudados não apresentaram alterações dos teores foliares de $\mathrm{Mg}$ em resposta à adubação, mas o cultivar Pérola apresentou teores foliares superiores aos do cultivar IAC Alvorada. De maneira geral, em todos os tratamentos os teores foliares de $\mathrm{P}, \mathrm{Ca}, \mathrm{Mg}$ e $\mathrm{S}$ ficaram dentro da faixa considerada adequada por Ambrosano et al. (1997), que é de 2,5 a $4,0 \mathrm{~g} \mathrm{~kg}^{-1}$ para o P, 10 a $25 \mathrm{~g} \mathrm{~kg}^{-1}$ para o $\mathrm{Ca}, 2,5$ a $5,0 \mathrm{~g}$ $\mathrm{kg}^{-1}$ para o Mg e de 2,0 a 3,0 $\mathrm{g} \mathrm{kg}^{-1}$ para o S. No caso do N, apenas os tratamentos não adubados apresentaram teores foliares abaixo do intervalo de 30 a $50 \mathrm{~g} \mathrm{~kg}^{-1}$, considerado adequado por Ambrosano et al. (1997). Os teores foliares de $\mathrm{K}$ em todos os tratamentos ficaram acima do intervalo de 20 a $24 \mathrm{~g} \mathrm{~kg}^{-1}$, considerado adequado por Ambrosano et al. (1997), possivelmente por causa do teor desse nutriente no solo, 3,0 $\mathrm{mmol}_{\mathrm{c}} \mathrm{dm}^{-3}$, considerado médio (Raij et al., 1997).

O número de folhas e a área foliar não foram influenciados pelos tratamentos nos primeiros 14 DAE (Figuras 1a e 1b). Em todos os tratamentos, o número de folhas e a área foliar aumentaram até por volta de 55 DAE, sendo que o número máximo de folhas e a máxima área foliar coincidiram com a fase de formação e desenvolvimento das estruturas reprodutivas (estádio $\mathrm{R}_{7}$ ). Elevados valores de área foliar nessa fase do ciclo do feijoeiro são importantes para elevada produção de fotoassimilados, que se- 
rão destinados ao crescimento dos grãos, já que, com maior área foliar, tem-se maior interceptação de luz e, consequentemente, maior produtividade de MS e de grãos (Portes, 1996).

A partir desta época houve senescência e abscisão foliar, diminuindo essas variáveis (Figuras 1a e 1b). Zucareli et al. (2010), em estudo sobre adubação fosfatada no feijoeiro cultivar Carioca Precoce, também observaram valores máximos de área foliar por volta de 55 DAE.

O cultivar IAC Alvorada, com a adubação recomendada (AD2), apresentou maior número de folhas por planta e maior área foliar, em relação aos dos demais tratamentos (Figuras 1a e 1b). Já os menores números de folhas por planta foram observados nos tratamentos do cultivar Pérola, especialmente sem adubação (PD0) e com $50 \%$ da dose recomendada (PD1). De maneira geral, o cultivar IAC Alvorada, quando comparado com o Pérola, especialmente nos maiores níveis de adubação, sempre apresentou maior número de folhas e maior área foliar por planta. Isso demonstra que, com a adubação recomendada, esse cultivar apresentou maior crescimento dos ramos (Figura 2a), que resultou em aumento mais expressivo do número de folhas e da área foliar, provavelmente por ser um cultivar mais responsivo à adubação mineral, em termos de crescimento vegetativo.

O IAF aumentou durante o período inicial do ciclo, atingindo os valores máximos, no tratamento AD2, próximo aos 60-65 DAE, enquanto, nos demais tratamentos, os valores máximos ocorreram aos 50 DAE (Figura 1c). Urchei et al. (2000) e Andrade et al. (2009) também obtiveram IAFs máximos na cultura do feijoeiro proximamente aos 50 DAE. No tratamento com o cultivar IAC Alvorada e adubação recomendada, o IAF foi superior ao obtido em todos os demais tratamentos, enquanto os menores valores de IAF foram observados no tratamento com o mesmo cultivar sem adubação. Esses resultados indicam que o cultivar IAC Alvorada apresenta maior crescimento, especialmente foliar, quando submetido à adubação recomendada. Verifica-se que o aumento do IAF entre 50 e 65 DAE deu-se pelo aumento do número de folhas e pela expansão do limbo foliar (Figuras 1a e 1b), como também observado por Sant'Ana \& Silveira (2008). A partir dessa fase, cessou a emissão de folhas novas e a perda por senescência superou a expansão foliar, diminuindo os valores de IAF.

A RAF foi semelhante em todos os tratamentos, diminuindo ao longo do ciclo (Figura 1d), em vista do surgimento e aumento da proporção de tecidos e de estruturas não assimilatórias (Figura 2c), além do autossombreamento, da senescência e da queda de folhas (Figuras 1a, 1b, 1c e 2b). Os valores mais elevados de RAF foram observados durante a fase inicial do ciclo, ou seja, durante a fase de crescimento vegetativo (Figura 1d), o que demonstra que, nessa fase, a maior parte do material fotossintetizado é convertida em folhas, visando a aumentar a captação de luz (Urchei et al., 2000; Falqueto et al., 2009), pois, nessa fase, as folhas chegaram a representar entre 66 e $84 \%$ da MS da parte aérea das plantas (Figuras 2b e 2d).

A RMF, que é o quociente entre a MS das folhas e a MS da parte aérea, não foi afetada pelos tratamentos, sendo que, em todos os tratamentos, os valores obtidos foram maiores nas fases iniciais do ciclo e diminuíram com a ontogenia das plantas (Figura 1e). Essa redução, observada ao longo do desenvolvimento, ocorreu por causa da menor fração de material retido nas folhas, ou seja, à maior exportação de fotoassimilados das folhas para as demais partes da planta (Jauer et al., 2003).

Até os 55 DAE, a AFE não foi influenciada pelos tratamentos, mas diminuiu neste período de desenvolvimento das plantas (Figura 1f), o que também foi observado em feijoeiro submetido a doses crescentes de $\mathrm{P}$ (Zucareli et al., 2010). A partir dos 70 DAE, a AFE foi

Tabela 1. Teores de macronutrientes na folha diagnose de cultivares de feijão sob diferentes níveis de adubação.

\begin{tabular}{|c|c|c|c|c|c|c|}
\hline \multirow{2}{*}{ Tratamentos $^{(1)}$} & $\mathbf{N}$ & $\mathbf{P}$ & $\mathbf{K}$ & $\mathbf{C a}$ & Mg & $\mathbf{S}$ \\
\hline & \multicolumn{6}{|c|}{$\mathrm{g} \mathrm{kg}^{-1}$} \\
\hline PD0 & $26 \mathrm{~b}$ & $3,1 \mathrm{a}$ & $25 \mathrm{~b}$ & $12,8 \mathrm{a}$ & $3,0 \mathrm{a}$ & $2,3 a$ \\
\hline PD1 & $37 \mathrm{a}$ & $3,3 \mathrm{a}$ & $29 a$ & $13,0 \mathrm{a}$ & $3,0 \mathrm{a}$ & $2,2 \mathrm{a}$ \\
\hline PD2 & $41 \mathrm{a}$ & $3,4 a$ & $29 a$ & $12,4 \mathrm{a}$ & $3,0 \mathrm{a}$ & $2,3 a$ \\
\hline $\mathrm{AD} 0$ & $24 b$ & $3,1 \mathrm{a}$ & $26 \mathrm{~b}$ & $12,6 \mathrm{a}$ & $2,3 b$ & $2,5 \mathrm{a}$ \\
\hline $\mathrm{AD} 1$ & $35 \mathrm{a}$ & $3,3 a$ & $29 a$ & $15,7 \mathrm{a}$ & $2,6 \mathrm{~b}$ & $2,2 \mathrm{a}$ \\
\hline $\mathrm{AD} 2$ & $40 \mathrm{a}$ & $3,3 a$ & $29 \mathrm{a}$ & $14,7 \mathrm{a}$ & $2,5 b$ & $2,5 \mathrm{a}$ \\
\hline $\operatorname{DMS}_{(0,05)}$ & 6,8 & 0,70 & 2,5 & 3,5 & 0,37 & 0,32 \\
\hline$\overline{\mathrm{CV}}(\%)$ & 13,3 & 14,2 & 6,0 & 15,5 & 9,0 & 8,1 \\
\hline
\end{tabular}

Médias seguidas de mesma letra, nas colunas, não diferem entre si pelo teste $\mathrm{t}(\mathrm{p} \leq 0,05)$. ${ }^{(1)} \mathrm{PD} 0=$ cultivar Pérola sem adubação; PD1 = cultivar Pérola com 50\% da adubação NPK recomendada; PD2 = cultivar Pérola com 100\% da adubação NPK recomendada; AD0 = cultivar IAC Alvorada sem adubação; AD1 = cultivar IAC Alvorada com 50\% da adubação NPK recomendada; AD2 = cultivar IAC Alvorada com 100\% da adubação NPK recomendada.

Rev. Ceres, Viçosa, v. 62, n.1, p. 107-116, jan/fev, 2015 
maior no tratamento $\mathrm{AD} 2$, por causa dos altos valores de área foliar e de IAF, ocorridos na fase final do ciclo, que aumentaram o autossombreamento (Figuras 1a, 1b, 1c e 1f). Em condições de menor disponibilidade de luz, as plantas investem maior proporção de fotoassimilados no aumento da área foliar, o que resulta em maior AFE e folhas com menor densidade de massa (Gobbi et al., 2011). Aumentos na AFE também podem indicar redu-
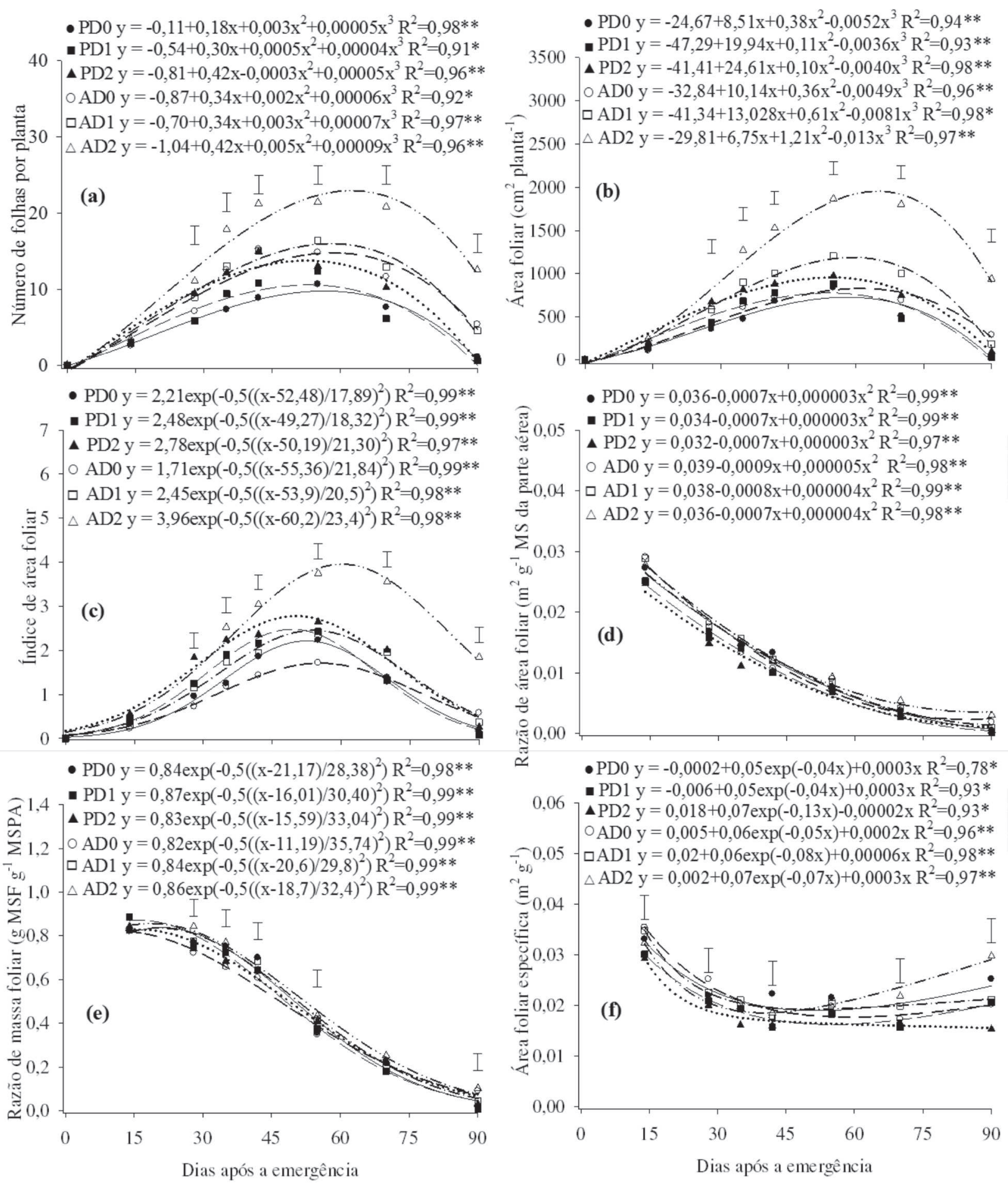

Figura 1. Número de folhas (a), área foliar (b), índice de área foliar (c), razão de área foliar (d), razão de massa foliar (e) e área foliar específica (f) de cultivares de feijão sob diferentes níveis de adubação. ** e * são: significativo a 1 e $5 \%$ de probabilidade pelo teste F. Barras verticais indicam o valor de DMS pelo teste $\mathrm{t}(\mathrm{p} \leq 0,05)$. PD0 = cultivar Pérola sem adubação; $\mathrm{PD} 1=$ cultivar Pérola com 50\% da adubação NPK recomendada; PD2 = cultivar Pérola com 100\% da adubação NPK recomendada; AD0 = cultivar IAC Alvorada sem adubação; AD1 = cultivar IAC Alvorada com 50\% da adubação NPK recomendada; AD2 = cultivar IAC Alvorada com 100\% da adubação NPK recomendada. MS = matéria seca; MSF =matéria seca foliar; MSPA = matéria seca da parte aérea. 
ção do conteúdo das folhas, quer pela expansão do limbo, quer pela migração dos produtos presentes nas folhas para suportar o crescimento de outras partes do vegetal (Jauer et al., 2003).
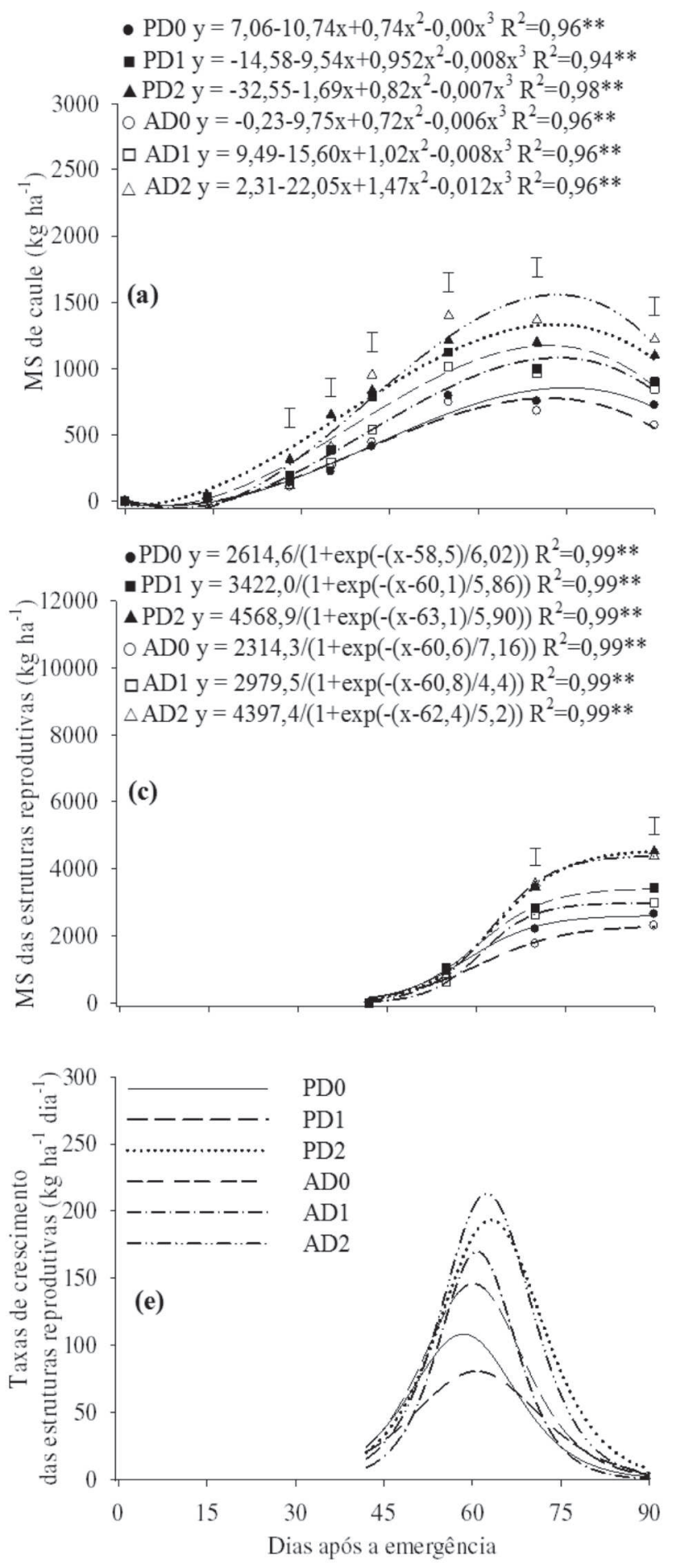

Em todos os tratamentos, o acúmulo de MS no caule aumentou até 70 DAE (estádio $\mathrm{R}_{8}$ ), com diminuição na fase seguinte (Figura 2a). Dentro de cada nível de adubação, ambos os cultivares acumularam quantidades se-
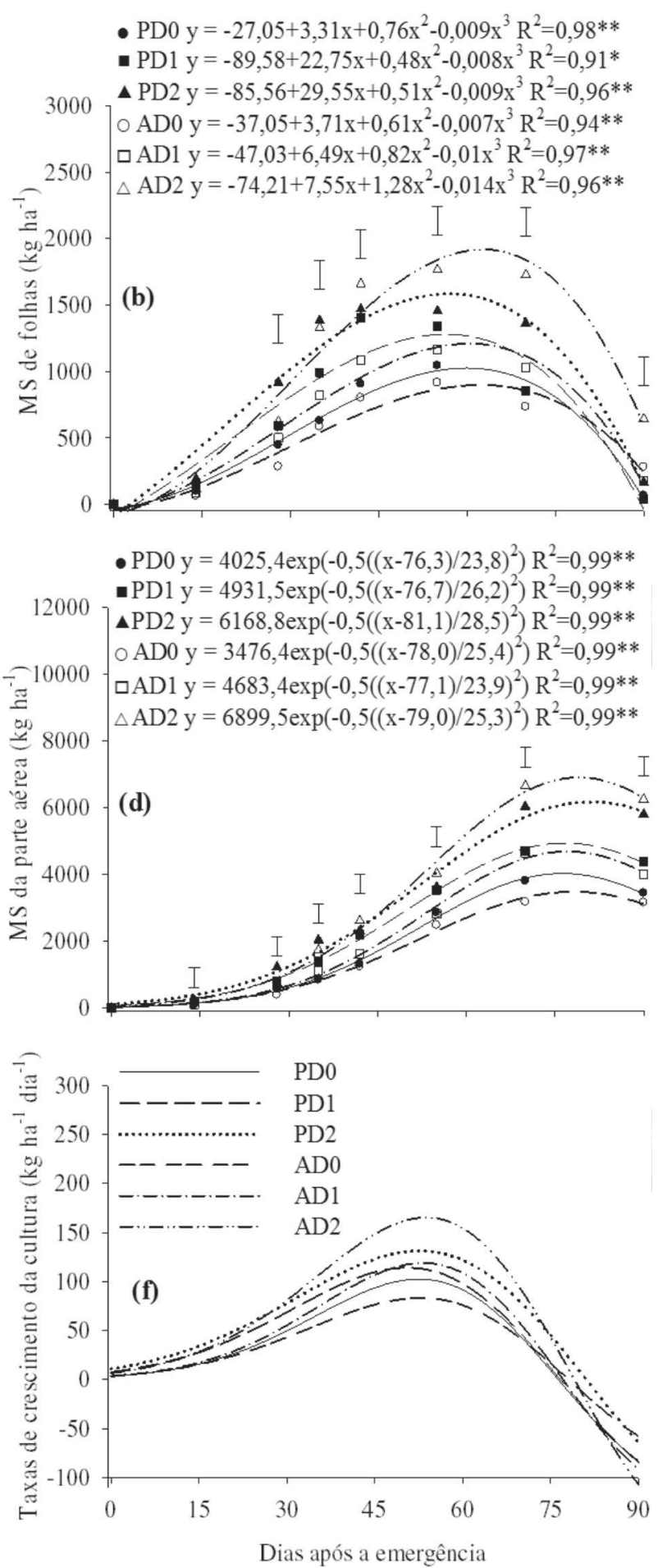

Figura 2. Acúmulo de matéria seca (MS) no caule (a), folhas (b), estruturas reprodutivas (c) e parte aérea (d) e taxas de crescimento das estruturas reprodutivas (e) e da cultura (TCCs) (f), de cultivares de feijão sob diferentes níveis de adubação. ** e * são: significativo a 1 e $5 \%$ de probabilidade pelo teste F. Barras verticais indicam o valor de DMS pelo teste $\mathrm{t}(\mathrm{p} \leq 0,05)$. PD0 = cultivar Pérola sem adubação; PD1 = cultivar Pérola com 50\% da adubação NPK recomendada; PD2 = cultivar Pérola com 100\% da adubação NPK recomendada; AD0 = cultivar IAC Alvorada sem adubação; AD1 = cultivar IAC Alvorada com 50\% da adubação NPK recomendada; AD2 = cultivar IAC Alvorada com 100\% da adubação NPK recomendada.

Rev. Ceres, Viçosa, v. 62, n.1, p. 107-116, jan/fev, 2015 
melhantes de MS no caule, porém, o acúmulo de MS aumentou com o incremento da quantidade de fertilizante aplicada. Até o florescimento (37 DAE), o caule acumulou entre 25 e $34 \%$ da MS da parte aérea das plantas, proporção essa que se manteve estável até o final do ciclo, apesar do crescimento intenso das estruturas reprodutivas, a partir dos 42 DAE (Figuras 2a, 2c e 2d). Andrade et al. (2009) também observaram apenas pequenas diminuições na MS do caule do feijoeiro, na fase final do ciclo, o que demonstra que, na fase final do ciclo, não ocorre grande remobilização de carboidratos do caule para o crescimento das vagens e grãos.

Nas folhas, os acúmulos de MS foram crescentes desde a emergência até entre 55 e 70 DAE $\left(R_{7}-R_{8}\right)$, independentemente do tratamento (Figura 2b). Sant'Ana \& Silveira (2008) observaram acúmulo máximo de MS nas folhas do feijoeiro, em época semelhante à observada neste estudo, ou seja, aos 66 DAE. Em todos os tratamentos, a senescência e abscisão foliar, na fase final do ciclo (Figuras 1a e 1b), reduziram a quantidade de MS acumulada nas folhas (Figura 2b), fato também observado por Andrade et al. (2009).

Os maiores acúmulos foliares de MS foram obtidos nos tratamentos que receberam a adubação NPK recomendada, com destaque para o cultivar IAC Alvorada, que apresentou MS foliar superior a do cultivar Pérola, principalmente, na fase final do ciclo (Figura 2b). Nos demais níveis de adubação, a MS foliar não diferiu entre os cultivares.

Até a fase de formação dos botões florais e início do florescimento (35-37 DAE) as folhas representaram entre 66 e $77 \%$ de toda MS acumulada na parte aérea das plantas, independentemente dos tratamentos (Figuras $2 \mathrm{~b}$ e $2 \mathrm{~d}$ ). A partir dessa época, por causa do crescimento das estruturas reprodutivas (Figura 2c) e da senescência foliar (Figuras 1a, 1b e 2b), houve alterações na distribuição da MS entre os órgãos das plantas, de modo que as folhas representaram menos de 3\% da MS da parte aérea do cultivar Pérola e por volta de $10 \%$ da MS do cultivar IAC Alvorada, no nível de adubação recomendado (Figuras 2b e 2d). Esses resultados demonstram que, com a adubação NPK recomendada, o cultivar IAC Alvorada destinou maior proporção de carboidratos para o crescimento das folhas que o cultivar Pérola, refletindo-se no aumento do número de folhas, da área foliar e do IAF (Figuras 1a, 1b e 1c).

Nos primeiros dias após o florescimento, o acúmulo de MS nas estruturas reprodutivas foi pequeno em todos os tratamentos, porém, com intenso incremento a partir dos 55 DAE, período em que as taxas de crescimento das estruturas reprodutivas atingiram os valores máximos (Figuras $2 \mathrm{c}$ e 2e). Após o início da formação das vagens (42 DAE), as estruturas reprodutivas passaram a ser os drenos principais das plantas e, nos tratamentos com a adubação NPK recomendada, por volta de 60-65 DAE as taxas de acúmulo de MS nas estruturas reprodutivas foram maiores que na parte aérea da planta, o que indica que havia realocação de MS dos demais órgãos da planta para as estruturas reprodutivas (Figuras 2e e 2f). Segundo Andrade et al. (2009), vagens e grãos funcionam como órgãos de armazenamento de carboidratos translocados das folhas. No final do ciclo, a MS nas estruturas reprodutivas representava entre 77 e $79 \%$ da MS da parte aérea do cultivar Pérola e entre 70 e $74 \%$ da MS do cultivar IAC Alvorada (Figuras 2c e 2d).

Os tratamentos com a adubação NPK recomendada (PD2 e AD2) proporcionaram maiores acúmulos e maiores taxas de acúmulo de MS nas estruturas reprodutivas (Figuras $2 \mathrm{c}$ e $2 \mathrm{e}$ ), o que se refletiu em produtividades de grãos mais elevadas (Tabela 2). Nos tratamentos com 50\% da adubação recomendada, ambos os cultivares apresentaram acúmulos e taxas de acúmulo de MS nas estruturas reprodutivas semelhantes e superiores àqueles dos trata-

Tabela 2. Componentes da produção e produtividade de grãos de cultivares de feijão sob diferentes níveis de adubação.

\begin{tabular}{|c|c|c|c|c|c|}
\hline \multirow[t]{2}{*}{ Tratamentos $^{(1)}$} & $\begin{array}{l}\text { População } \\
\text { final }\end{array}$ & \multirow[t]{2}{*}{$\begin{array}{c}\text { Número de vagens } \\
\text { por planta }\end{array}$} & \multirow[t]{2}{*}{$\begin{array}{c}\text { Número de grãos } \\
\text { por vagem }\end{array}$} & \multirow{2}{*}{$\begin{array}{c}\text { Massa de } \\
100 \text { grãos }\end{array}$} & \multirow{2}{*}{$\begin{array}{c}\begin{array}{c}\text { Produtividade } \\
\text { de grãos }\end{array} \\
\text { kg ha }^{-1}\end{array}$} \\
\hline & mil plantas ha-1 & & & & \\
\hline PD0 & $273 a$ & $6,4 \mathrm{~d}$ & $4,5 b$ & $29,2 \mathrm{bc}$ & $2.033 \mathrm{c}$ \\
\hline PD1 & $277 \mathrm{a}$ & $7,7 \mathrm{~d}$ & $4,6 a b$ & $32,8 \mathrm{ab}$ & $2.992 b$ \\
\hline PD2 & $271 \mathrm{a}$ & $9,6 \mathrm{c}$ & $4,8 \mathrm{a}$ & $33,6 a$ & $3.898 \mathrm{a}$ \\
\hline AD0 & $206 b$ & $10,3 \mathrm{c}$ & $3,6 \mathrm{~d}$ & $28,9 \mathrm{c}$ & $1.866 \mathrm{c}$ \\
\hline $\mathrm{AD} 1$ & $197 b$ & $12,4 \mathrm{~b}$ & $3,9 \mathrm{c}$ & $30,7 \mathrm{abc}$ & $2.572 \mathrm{~b}$ \\
\hline $\mathrm{AD} 2$ & $199 b$ & $15,1 \mathrm{a}$ & $4,0 \mathrm{c}$ & $32,3 \mathrm{abc}$ & $3.657 \mathrm{a}$ \\
\hline $\operatorname{DMS}_{(0,05)}$ & 40,6 & 1,5 & 0,21 & 3,8 & 424,8 \\
\hline$\overline{\mathrm{CV}}(\%)$ & 11,4 & 10,1 & 3,3 & 8,1 & 10,0 \\
\hline
\end{tabular}

Médias seguidas de mesma letra, nas colunas, não diferem entre si pelo teste t $(\mathrm{p} \leq 0,05) .{ }^{(1)} \mathrm{PD} 0=$ cultivar Pérola sem adubação; PD1 = cultivar Pérola com 50\% da adubação NPK recomendada; PD2 = cultivar Pérola com 100\% da adubação NPK recomendada; AD0 = cultivar IAC Alvorada sem adubação; AD1 = cultivar IAC Alvorada com 50\% da adubação NPK recomendada; AD2 = cultivar IAC Alvorada com 100\% da adubação NPK recomendada. 
mentos sem adubação. Esse padrão de crescimento e de acúmulo de MS nas estruturas reprodutivas refletiu-se na produtividade de grãos, ou seja, com produtividades de grãos intermediárias e semelhantes nos tratamentos com metade da adubação NPK recomendada e produtividades menores nos tratamentos sem adubação (Tabela 2).

Em todos os tratamentos, o acúmulo de MS na parte aérea foi pequeno nos primeiros $28 \mathrm{DAE}$, mas se intensificaram, especialmente após o florescimento, em função do crescimento intenso das estruturas reprodutivas e das elevadas taxas de crescimento da cultura (TCCs), observadas após essa época (Figuras $2 \mathrm{~d}$ e 2f). Em todos os tratamentos, as TCCs foram crescentes até os $55 \mathrm{DAE}$, mas o acúmulo de MS na parte aérea aumentou até por volta de 80 DAE, período em que as TCCs tornaram-se negativas e as quantidades de MS acumuladas diminuíram até o final do ciclo, em decorrência da redução da área e da MS foliar (Figuras 1b, 2b, 2d e 2f). Resultados semelhantes foram observados por Jauer et al. (2003), para o cultivar Pérola, e por Vieira et al. (2008), para o cultivar de feijão BRSMG Talismã. Estes resultados indicam que os valores máximos da TCC normalmente coincidem com o período de crescimento de vagens e início de enchimento de grãos. Nota-se que os tratamentos com a adubação recomendada apresentaram valores de acúmulo de MS na parte aérea e TCCs semelhantes entre os cultivares, mas superiores aos dos demais, enquanto os tratamentos sem adubação apresentaram os menores valores dessas variáveis (Figuras $2 \mathrm{f}$ e $2 \mathrm{~d}$ ). Apesar da menor população de plantas nos tratamentos com o cultivar IAC Alvorada, não houve diferenças na produção de MS, o que se deve à plasticidade, ou seja, a capacidade das plantas de feijoeiro tipo III de se adaptarem ao ambiente (Jauer et al., 2003).

A TCR, que expressa o incremento de MS em relação à biomassa pré-existente, foi sempre decrescente para todos os tratamentos ao longo do ciclo (Figura 3a), atingindo valores negativos na última avaliação, por causa do aumento de tecidos não assimilatórios, como as estruturas reprodutivas, e da perda de folhas (Figuras 1a, 1b e 2c). Urchei et al. (2000), Jauer et al. (2003) e Zucareli et al. (2010) também verificaram comportamento decrescente da TCR ao longo do ciclo do feijoeiro, independentemente dos tratamentos testados, o que é explicado pelo autossombreamento crescente e pela produção de órgãos não fotossintetizantes. Apenas aos 35 DAE, a TCR foi maior nos tratamentos AD2 e AD0, enquanto os tratamentos PD2 e PD0 apresentaram menores valores (Figura 3a), indicativos de menor eficiência de conversão de MS (Urchei et al., 2000; Falqueto et al., 2009). Porém, a partir dos 42 DAE, não houve diferença entre os tratamentos.

A TAL praticamente não variou entre os tratamentos durante a maior parte do ciclo, com os maiores valores ocorrendo aos 14 DAE (Figura 3b). Estes resultados refletem a menor área foliar do feijoeiro, nessa época (Figura 1b), em contrapartida à elevada capacidade fotossintética das folhas jovens, o que está de acordo com os resultados obtidos por Andrade et al. (2009), para cultura do feijão. Nas fases seguintes, os valores da TAL diminuíram, porém, apresentaram uma tendência de estabilização entre
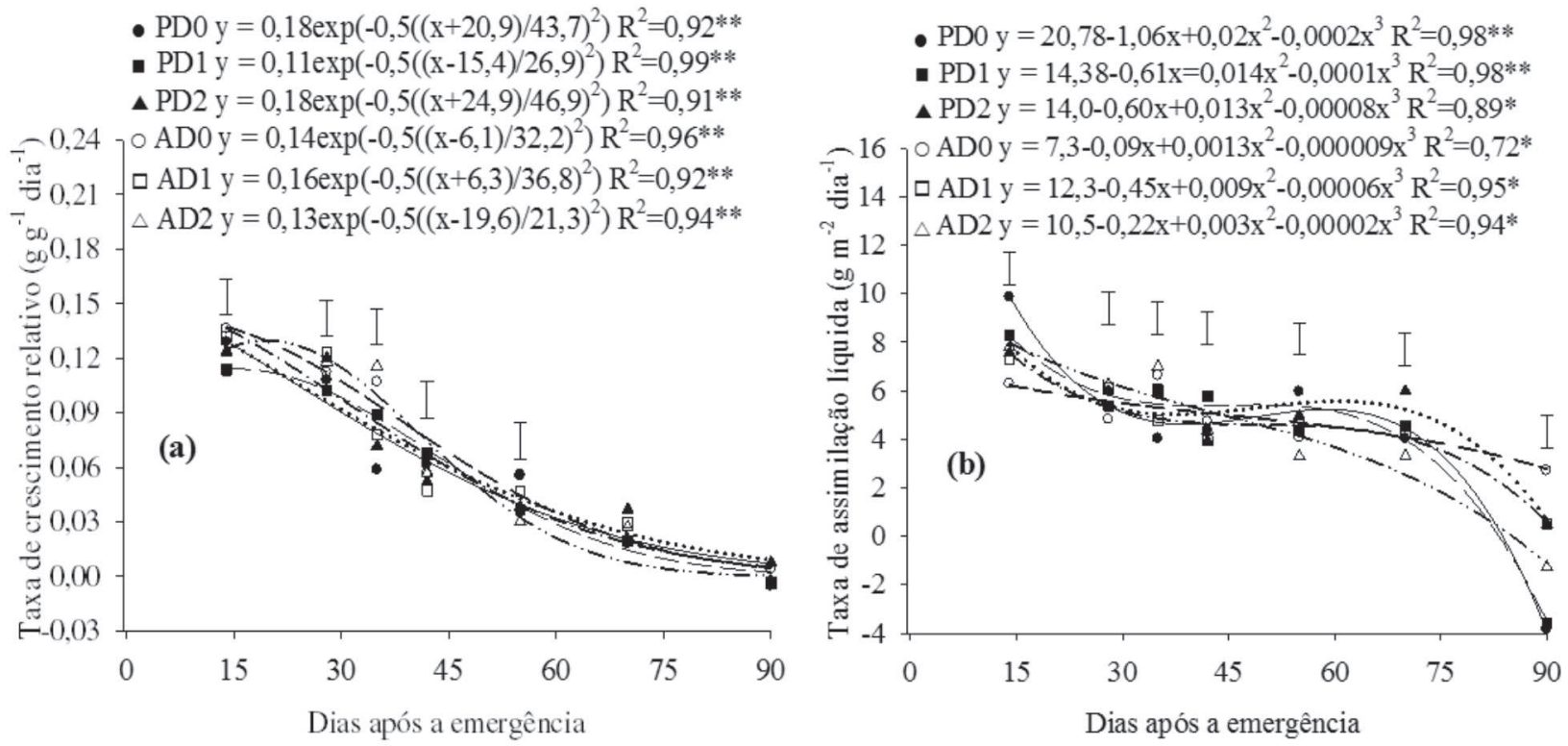

Figura 3. Taxa de crescimento relativo (a) e taxa de assimilação líquida (b) de cultivares de feijão sob diferentes níveis de adubação. **e e são: significativo a 1 e $5 \%$ de probabilidade pelo teste F. Barras verticais indicam o valor de DMS pelo teste $\mathrm{t}(\mathrm{p} \leq 0,05)$. PD0 = cultivar Pérola sem adubação; PD1 = cultivar Pérola com 50\% da adubação NPK recomendada; PD2 = cultivar Pérola com 100\% da adubação NPK recomendada; AD0 = cultivar IAC Alvorada sem adubação; AD1 = cultivar IAC Alvorada com 50\% da adubação NPK recomendada; AD2 = cultivar IAC Alvorada com 100\% da adubação NPK recomendada.

Rev. Ceres, Viçosa, v. 62, n.1, p. 107-116, jan/fev, 2015 
28 e 70 DAE, seguida de decréscimo acentuado na fase final do ciclo (Figura 3b), semelhantemente aos resultados obtidos por Urchei et al. (2000), em feijoeiro irrigado. Esse período de manutenção da TAL coincide com a fase de maior TCC e, apesar da manutenção da eficiência fotossintética das folhas, o IAF elevado proporcionou maiores valores de TCC (Figuras 1c, 2f e 3b). Em geral, há tendência de diminuição da TAL com a expansão foliar, principalmente em virtude do autossombreamento (Andrade et al., 2009), o que foi observado em todos os tratamentos. Verifica-se que, na fase final do ciclo, apenas os tratamentos PD0, PD1 e AD2 apresentaram valores de TAL negativos, enquanto, no tratamento AD0, os valores de TAL foram $3 \mathrm{~g} \mathrm{~m}^{-2} \mathrm{dia}^{-1}$, e, nos demais, ficaram próximos de zero (Figura 3b).

Apesar dos elevados valores de IAF no tratamento AD2, o acúmulo de MS na parte aérea das plantas desse tratamento não diferiu daquele do tratamento PD2, provavelmente, em função do autossombreamento que deve ter ocorrido após os $42 \mathrm{DAE}$, por aumento intenso do IAF (Figuras 1c e 2d). Isso causou, nas plantas do tratamento AD2, diminuição mais acentuada dos valores da TCC e da TAL após os 55 DAE, em comparação com os do tratamento PD2 (Figuras 2f e 3b).

A população final de plantas de ambos os cultivares não foi alterada pela adubação NPK, porém, em todos os tratamentos com o cultivar Pérola a população de plantas foi maior que a dos tratamentos com o cultivar IAC Alvorada (Tabela 2). As menores populações nos tratamentos com o cultivar IAC Alvorada podem ser atribuídas, em parte, ao poder germinativo das sementes, apesar de na semeadura terem sido utilizadas 15 sementes por metro de sulco.

De modo geral, os tratamentos com o cultivar IAC Alvorada apresentaram maior número de vagens por planta e menor número de grãos por vagem, que os tratamentos com o cultivar Pérola (Tabela 2). A massa de 100 grãos diferiu apenas entre o tratamento PD2 (33,6 g) e os tratamentos PD0 (29,2 g) e AD0 (28,9 g), enquanto, nos demais tratamentos, a massa de grãos foi semelhante. De maneira geral, o aumento da quantidade de adubo incrementou o número de vagens por planta, o número de grãos por vagem e a massa de 100 grãos de ambos os cultivares (Tabela 2).

A produtividade de grãos não diferiu entre os cultivares, em cada nível de adubação estudado, mas ambos os cultivares apresentaram aumentos significativos de produtividade com o incremento da adubação NPK (Tabela 2). Os resultados indicam que, na ausência de adubação, a menor disponibilidade de nutrientes, especialmente de $\mathrm{N}$, limitou o crescimento e a produtividade de grãos de ambos os cultivares de feijão (Tabela 2 e Figura 2). Os maiores números de vagens por planta dos tratamentos do cultivar IAC Alvorada compensaram a menor população de plantas e o menor número de grãos por vagem desses tratamentos, refletindo-se em produtividades de grãos semelhantes às dos tratamentos com o cultivar Pérola. Esses resultados evidenciam que o cultivar IAC Alvorada, cultivado com a adubação NPK recomendada, mesmo com menor população de plantas, apresentou maior IAF que a dos demais tratamentos, porém, o acúmulo de MS na parte aérea e a produtividade de grãos não diferiram dos do cultivar Pérola, nos mesmos níveis de adubação.

\section{CONCLUSÕES}

A adubação NPK aumentou de forma semelhante os acúmulos de matéria seca na parte aérea, os componentes da produção e a produtividade de grãos dos cultivares Pérola e IAC Alvorada.

Com o uso da adubação NPK recomendada, o cultivar IAC Alvorada apresentou maior índice de área foliar e maior acúmulo de matéria seca nas folhas que o 'Pérola', porém, isso não se refletiu em maior produtividade de grãos.

O máximo acúmulo de matéria seca na parte aérea foi alcançado aos 80 DAE e a maior taxa de crescimento da cultura ocorreu aos $55 \mathrm{DAE}$, independentemente do tratamento.

\section{AGRADECIMENTOS}

À FAPESP, pela concessão de bolsa de Iniciação Científica à primeira autora (Proc. 2010/18602-9). Ao CNPq, pela concessão de bolsa de Produtividade em Pesquisa, ao segundo autor.

\section{REFERÊNCIAS}

Ambrosano EJ, Tanaka RT, Mascarenhas AA, Raij B van, Quaggio JA \& Cantarella H (1997) Feijão. In: Raij Bvan, Cantarela H, Quaggio JA \& Furlani AMC (Eds.) Recomendações de adubação e calagem para o Estado de São Paulo. $2^{a}$ ed. Campinas, IAC. p.189-195. (Boletim Técnico, 100).

Andrade CAB, Scapim CA, Braccini AL \& Martorelli DT (2009) Produtividade, crescimento e partição de matéria seca em duas cultivares de feijão. Acta Scientiarum Agronomy, 31:683-688.

Benincasa MMP (2003) Análise de crescimento de plantas: noções básicas. $2^{\mathrm{a}}$ ed. Jaboticabal, Funep. 41 p.

Borém A \& Carneiro JES (2006) A cultura. In: Vieira C, Paula Júnior TJ \& Borém A (Eds.) Feijão. $2^{\mathrm{a} e d . ~ V i c ̧ o s a, ~ U F V . ~ p .13-18 . ~}$

Carbonell SAM, Chiorato AF, Ito MF, Perina EF, Gonçalves JGR, Souza OS, Gallo PB, Ticelli M, Colombo CA \& Azevedo Filho JA(2008) IACAlvorada and IAC-Diplomata: new common bean cultivars. Crop Breeding and Applied Biotechnology, 8:163-166.

Conceição MK, Lopes NF \& Fortes GRL (2004) Partição de matéria seca entre órgãos de batata-doce (Ipomoea batatas (L.) Lam), cultivares Abóbora e Da Costa. Revista Brasileira de Agrociência, 10:313-316.

Falqueto AR, Cassol D, Magalhães Júnior AM, Oliveira AC \& Bacarin MA (2009) Crescimento e partição de assimilados em cultivares de arroz diferindo no potencial de produtividade de grãos. Bragantia, 68:563-571. 
Gobbi KF, Garcia R, Ventrella MC, Garcez Neto AF \& Rocha GC (2011) Área foliar específica e anatomia foliar quantitativa do capimbraquiária e do amendoim-forrageiro submetidos a sombreamento. Revista Brasileira de Zootecnia, 40:1436-1444

Gomes AA, Araújo AP, Rossiello ROP \& Pimentel C (2000) Acumulação de biomassa, características fisiológicas e rendimento de grãos em cultivares de feijoeiro irrigado e sob sequeiro. Pesquisa Agropecuária Brasileira, 35:1927-1937.

Jauer A, Dutra LMC, Zabot L, Lucca Filho AO, Losekann ME, Uhry D, Stefanelo D, Farias JR \& Ludwig MP (2003) Análise de crescimento da cultivar de feijão Pérola em quatro densidades de semeadura Revista da Faculdade de Zootecnia, Veterinária e Agronomia de Uruguaiana, 10:101-113.

Malavolta E, Vitti GC \& Oliveira AS (1997) Avaliação do estado nutricional de plantas: princípios e aplicações. Piracicaba, Associação Brasileira para Pesquisa da Potassa e do Fosfato. 308p.

Melo CLP, Carneiro JES, Carneiro PCS, Cruz CD, Barros EG \& Moreira MA (2006) Linhagens de feijão do cruzamento ‘Ouro Negro' x 'Pérola’ com características agronômicas favoráveis. Pesquisa Agropecuária Brasileira, 41:1593-1598.

Portes TA (1996) Ecofisiologia. In: Araújo RS, Rava CA, Stone LF \& Zimmermann MJO (Eds.) Cultura do feijoeiro comum no Brasil. Piracicaba, Potafós. p.101-137.
Raij B van, Cantarella H, Quaggio JA \& Furlani AMC (1997) Recomendações de adubação e calagem para o Estado de São Paulo. Campinas, Instituto Agronômico/Fundação IAC. 285p. (Boletim Técnico, 100).

Sant' ana EVP \& Silveira PM (2008) Crescimento do feijoeiro (Phaseolus vulgaris L.) influenciado por doses de nitrogênio em cobertura. Pesquisa Agropecuária Tropical, 38:134-140.

Soratto RP, Fernandes AM, Souza EFC \& Souza-Schlick GD (2011) Produtividade e qualidade dos grãos de feijão em função da aplicação de nitrogênio em cobertura e via foliar. Revista Brasileira de Ciência Solo, 35:2019-2028.

Urchei MA, Rodrigues JD \& Stone LF (2000) Análise de crescimento de duas cultivares de feijoeiro sob irrigação, em plantio direto e preparo convencional. Pesquisa Agropecuária Brasileira, 35:497-506.

Vieira C (2006) Adubação mineral e calagem. In: Vieira C, Paula Júnior TJ \& Borém A (Eds.) Feijão. $2^{a}$ ed. Viçosa, UFV. p.115-142.

Vieira NMB, Andrade MJB, Carvalho JG, Alves Júnior J \& Morais AR (2008) Altura de planta e acúmulo de matéria seca do feijoeiro cvs. BRS MG Talismã e Ouro Negro em plantio direto e convencional. Ciência e Agrotecnologia, 32:1687-1693.

Zucareli C, Ramos Júnior EU, Oliveira MA, Cavariani C \& Nakagawa J (2010) Índices biométricos e fisiológicos em feijoeiro sob diferentes doses de adubação fosfatada. Semina: Ciências Agrárias, 31:13131324. 